\title{
Factors Affecting the Pregnancy Outcome in Patients with Previous One Caesarean Section
}

\author{
Begum $\mathrm{KS}^{1}$, Khan $\mathrm{NU}^{2}$, Akter $\mathrm{F}^{3}$
}

\begin{abstract}
This case series study was designed to determine the factors affecting the pregnancy out come in patients with previous one caesarean section.

The study was conducted at Marie Stopes Clinic Primium-1 Dhanmondi from July 01, 2012 to January 31, 2013.

A total of 150 patients with previous one caesarean section who presented at term were included in the study. The data were collected through proforma and subjected to statistical analysis.
\end{abstract}

Out of 150 patients, 81 (54\%) patients had trial of scar and the remaining 69 (46\%) patients underwent repeat elective caesarean section. Among those who had trial of scar only $35(43.2 \%)$ patients achieved successful vaginal delivery and remaining $46(56.8 \%)$ had emergency caesarean section. Common indication for repeat emergency caesarean section was non progress of labour (47.8\%). It was frequent in women who reported late to hospital after the onset of labour and in women who did not seek antenatal booking in pregnancy. Maternal complications like post partum hemorrhage, scar dehiscence, wound infection and febrile illness were more in those who had emergency caesarean section. There was no maternal mortality in the study. Perinatal outcome was not affected by the mode of delivery. There were two perinatal deaths which occurred in non-booked patients who underwent emergency caesarean section.

Most of the women in our study had repeat caesarean section for failed progress. Regular antenatal check up and early report to hospital after the onset of labour can reduce the rate of repeat caesarean section.

Key words: Caesarean Section, Vaginal birth after caesarean section.

\section{Introduction}

The rising incidence of caesarean section all over the world has been of great concern both to the patients and obstetrician$^{1}$. Repeat caesarean section is one of the major reasons which have contributed greatly to high caesarean section rate ${ }^{2}$. Cragin's once section always caesarean section must be abandoned and replaced by once a caesarean always a hospital delivery. Vaginal birth after caesarean section should be practiced in properly staffed and well equipped

1. Corresponding Author:

Dr. Kazi Shahnaz Begum

Assistant Professor, Department of Gynae \& Obstetrics

MARKS Medical College and Hospital, Mirpur, Dhaka

2. Dr. Neyamat Ullah Khan

Assistant Professor, Department of ENT-Head \& Neck Surgery MH Samorita Medical College and Hospital, Dhaka

3. Dr. Farhana Akter

Medical Officer

Marie Stopes Clinic Premium, Dhanmondi, Dhaka hospitals. Pitkin RM 3 aptly stated, "Many women with previous caesarean can be delivered vaginally and thereby gain substantial advantage, but neither the decision for trial of labour nor management during labour should be arrived at in a cavalier or superficial manner ${ }^{3}$.

Vaginal birth after caesarean section has been recommended, however, there are variations in patient's characteristics, which limit this practice. Trial of scar depends on the appropriate selection criteria, which include non-recurrent previous indication, known uterine incision and good maternal and foetal health in ongoing pregnancy. The present study was undertaken to identify factors which are responsible for the repeat caesarean section in our population.

\section{Materials and Methods}

This case series study was undertaken at Marie Stopes Clinic, Primium-1, Dhanmondi from July 01, 2012 to January 31, 2013. Convenient sampling was done. All multiparous women with previous one lower segment caesarean section who presented at term ( 37 completed weeks to 42 weeks) were included in the study. All women with history of previous classical caesarean section were excluded.

The data were recorded through proforma. It described the patient's characteristics including age, parity, booked, nonbooked status, past obstetric medical and surgical history, history of present pregnancy and complication.

Patients selected for trial of labour were strictly monitored. Maternal and foetal condition including progress of labour was recoded on partogram. Mode of delivery was specifically recorded. In case of vaginal delivery it was recorded whether it had spontaneous vaginal delivery, forceps or ventouse extraction. Maternal complications developed during or after the labour were noted for example, Scar Tenderness, Scar Dehiscence, PPH, Wound Infection and Febrile Morbidity.

Statistical Analysis the data were analysed through SPSS version 10 and various descriptive statistics were used to calculate frequencies, percentages, means and standard deviation.

\section{Results}

150 cases were included in the study that fulfilled the inclusion criteria. Numbers of booked cases delivered vaginally, through emergency caesarean section and elective caesarean section were $20(57 \%) 10(21 \%)$ and $37(56 \%)$ respectively. Numbers of non-booked cases delivered vaginally, through emergency caesarean section and elective caesarean section were $15(42 \%), 36(78 \%)$ and $32(46.3 \%)$ P-Value $<0.000$, $<0.000,<0.051$ respectively.

Repeat emergency caesarean section was performed in $46(56.8 \%)$ cases. Majority (78\%) were non-booked and 22\% were booked. There were $69(46 \%)$ cases of elective caesarean section and $46(30.7 \%)$ cases of emergency caesarean section. The remaining 35 (23.3\%) cases were delivered vaginally. 
Table I: Indications for Elective Caesarean Section in the Study

\begin{tabular}{lcc}
\hline Indications & Number & $\mathbf{\%}$ \\
\hline Cephalo Pelivic Disproportion & 21 & 30.4 \\
Bad Obstructed History & 12 & 17.3 \\
Breech & 09 & 13.0 \\
Post Date & 08 & 11.5 \\
Diabetes & 06 & 8.6 \\
IUGR & 05 & 7.2 \\
Twins & 04 & 6.0 \\
Repaired 3rd Degree Tear & 02 & 3.0 \\
Pre-Eclampsia & 02 & 3.0 \\
\hline Total & $\mathbf{6 9}$ & $\mathbf{1 0 0}$
\end{tabular}

Table I shows indications for elective caesarean section. There were $21(30.4 \%)$ patients who underwent elective caesarean section for cephalo-pelvic disproportion, 12(17.3\%) for bad of obstetric history and $9(13 \%)$ for breech presentation.

Table II: Indications for Emergency Caesarean Section in the Study $(n=46)$

\begin{tabular}{lcc}
\hline Indications & Number & $\mathbf{\%}$ \\
\hline Non-Progress of Labour & 22 & $47.8 \%$ \\
Foetal Distress & 07 & $15.2 \%$ \\
Premature Rupture of & & \\
Membranes $>12$ hours & 05 & $11.0 \%$ \\
Poor Biophysical Profile & 04 & $8.6 \%$ \\
Scar Tenderness & 03 & $6.6 \%$ \\
Twins in Labour & 02 & $4.2 \%$ \\
Placenta Previa & 01 & $2.2 \%$ \\
Abruption & 01 & $2.2 \%$ \\
Deep Transverse Arrest & 01 & $2.2 \%$ \\
\hline Total & $\mathbf{4 6}$ & $\mathbf{1 0 0 . 0 0 \%}$
\end{tabular}

Table II Shows indication for emergency caesarean section in study group $(n=46)$. There were $22(47.8 \%)$ patients underwent emergency caesarean section for non-progress of labour.

Table III: shows Perinatal Outcome in the Patients $(n=150)$

\begin{tabular}{lcccc}
\hline \multicolumn{1}{c}{ Perinatal } & Vaginal & Emergency & Elective & P-value \\
\hline Outcome & delivery & $(\mathrm{n}-35)$ & $\mathrm{C} / \mathrm{S}(\mathrm{n}-46)$ & $\mathrm{C} / \mathrm{S}(\mathrm{n}-60)$ \\
Mean Birth Weight & $3.2 \mathrm{~kg}$ & $3.0 \mathrm{~kg}$ & $3.0 \mathrm{~kg}$ & 0.051 \\
Jaundice & $4(11.4 \%)$ & $6(13.0 \%)$ & $2(2.9 \%)$ & 0.00 \\
Neonatal Sepsis & $5(14.2 \%)$ & $9(19.6 \%)$ & $3(4.3 \%)$ & 0.00 \\
Perinatal Death & -- & 2 & -- & 0.00 \\
\hline
\end{tabular}

In vaginal deliveries, there were $4(11.4 \%)$ cases developed jaundice, $5(14.2 \%)$ cases developed neonatal sepsis. In emergency C/S 6(13\%) cases developed jaundice, 9(19.6\%) cases developed sepsis, perinatal death occur in 2 cases. In elective $\mathrm{C} / \mathrm{S} 2(2.9 \%)$ cases developed jaundice, 3(4.3\%) cases developed sepsis.
Table IV: Postnatal Complications

Vaginal delivery Emergency $\mathrm{C} / \mathrm{S}$ Elective $\mathrm{C} / \mathrm{S}$

\begin{tabular}{lccc}
\hline Primary PPH & $2(5.7 \%)$ & $5(10.9 \%)$ & $2(2.9 \%)$ \\
Febrile illness & $1(2.8 \%)$ & $4(8.7 \%)$ & $1(1.5 \%)$ \\
Wound infection & -- & $3(6.5 \%)$ & $2(2.9 \%)$ \\
\hline
\end{tabular}

In vaginal deliveries, there were $2(5.7 \%)$ cases of primary PPH and only $1(2.8 \%)$ case of febrile illness. In emergency caesarean section, there were $5(10.9 \%)$ cases of primary $\mathrm{PPH}, 4(8.7 \%)$ cases of febrile morbidity, $3(6.5 \%)$ cases of wound infection. In elective caesarean section there were $2(2.9 \%)$ cases of primary PPH, $1(1.5 \%)$ cases of febrile illness, $2(4.3 \%)$ cases of wound infection.

\section{Discussion}

There is widespread public and professional concern about the increasing proportion of births by caesarean section ${ }^{4}$. Many factors have been put forward in international journals for the upward trend of caesarean section, like reduced parity, older primipara, use of electronic foetal monitoring, delivery of breech by caesarean section, less use of forceps, fear of litigation and high socio-economic status $\mathrm{s}^{5,18}$. The percentage of women undergoing caesarean section is rising.

In our study, only $81(54 \%)$ case were chosen for trial of scar, which is lower than the compared data, which is $62 \%$ in a study at Agha Khan University, Karachi and another study it was $80 \%$ from $\mathrm{UAE}^{6,7}$. In a study in India $27.7 \%$ had successful vaginal delivery while $72.3 \%$ had a repeat cesarean section. Maternal morbidity and perinatal mortality were both significantly higher in the vaginal delivery group $(\mathrm{P}=0.00211 \text { and } \mathrm{P}=0.0426 \text {, respectively })^{8}$.

The discrepancy reflects the inherent differences in the obstetric population and criteria used for selection of cases. In our study $46(56.8 \%)$ had repeat emergency caesarean section and only $35(43.2 \%)$ achieved successful vaginal delivery. In another study from UK, success rate of vaginal birth was as high as $60 \%$ with no foetal or maternal complication 9 . While in other studies, it was quoted as $65 \%, 77 \%$ and $81 \%$ 10-12. Among VBAC candidates who have had a prior vaginal delivery, those who attempt a VBAC trial have decreased risk for overall major maternal morbidities, as well as maternal fever and transfusion requirement compared with women who elect repeat cesarean delivery ${ }^{13}$.

In different studies risk factors for unsuccessful VBAC are: induced labour, no previous vaginal birth, body mass index greater than 30 and previous caesarean section for dystocia $^{14-16}$.

Main indication for the repeat emergency caesarean section was non - progress of labour in $22(47.8 \%)$ cases followed by foetal distress $7(15 \%)$, premature rupture of membrane $5(11 \%)$, scar tenderness $3(6.5 \%)$ etc (Table 2$)$. It is comparable to other data in which failure to progress was the main reason for the repeat $\operatorname{scar}^{17}$.

Maternal complications were the same irrespective of the route of delivery. These included primary post-partum hemorrhage, febrile morbidity, wound infection and scar dehiscence (Table 4$)^{18}$. The complications were however more in cases of repeat versus elective caesarean section ${ }^{19}$. 
In a study of trial of labour versus elective caesarean section, major complications were more in women undergoing trial of scar ${ }^{11}$. There was no case of maternal mortality in our study. Maternal mortality rate has been cited in other study as $0.37 / 1000$ in $1982-1984^{20}$.

Mean birth weight of babies was not different in the patients delivered either through vaginal or abdominal route (Table 3 ). Foetal weight had greater influence on the route of delivery in a study but in another study $50 \%$ UK obstetrician did not see a clinically big baby as contra indication to a trial of labour ${ }^{21}$. There is generally a non-consensus that clinically or ultrasonic evidence of macrosomia affects the choice of delivery. In this study foetal complications were not much affected by the route of delivery. Apgar score at 0 minute and 5 minutes were same in patients whether delivered through vaginal or abdominal route. In another study similar to our own emergency cesarean section was more likely than elective to result in a perinatal loss. While in a study the respiratory morbidity was higher in infants delivered by elective caesarean section before the onset of labour ${ }^{9}$, because these fetuses do not have physiological stress of labour however our study did not substantiate these events.

Success rate of vaginal birth after caesarean section in our study is very low compared to other studies. We associated it with the large numbers of non-booked patients who present in established or advanced labour with associated foetal medical or obstetric problems, which lowered the threshold for repeat caesarean section by the consultant obstetrician. Majority of them are already being mismanaged and cannot be subjected to trial of scar without further jeopardizing maternal/foetal condition

In this study most of the women had repeat caesarean section. The reasons in most cases were late referral to Clinic. Majority of them were in established or advanced labour with associated foetal, medical and/or obstetric problems. This lowered the threshold for repeat caesarean section by consultant obstetrician. This situation limited the number of the cases which could be subjected to trial of labour. Mode of delivery also depends upon the suitability of cases chosen for trial of scar. Regular antenatal check-up and early report to hospital after the onset of labour can reduce the rate of repeat emergency caesarean section. Patients and their families with primary caesarean section must be counseled during their stay in hospital and during follow up visits for the need of regular antenatal check-up in pregnancy.

\section{References}

1. Jane Thomas, Alison Callwood, Peter Brocklehurst, James Walker, The National Sentinel Caesarean Section Audit BMJ of Obst Gynaecol 2000;107:579-580

2. Stuart I, Burn R and Duncan LS. Reducing C-Section rate in a rural community hospital. Can Med Assoc J $1991 ; 145: 1459-60$

3. Pitkin R M. Once a caesarean? Obstet Gynaecol 1991;77:939

4. Parliamentary office of science and technology. Caesarean section. Post note 2002;184:1-4

5. Goldman G, Pineault R, Potvin L, Blais R, BIlodeau H.
Factors influencing the practice of vaginal birth after caesarean section. Am J Public Health 1993;8:1104-8

6. F Shaheen, Vaginal Birth after Caesarean Section: A Three Year Study, Pak. J. Obst. Gynecol 1997;10:18-21

7. Khan GQ and Thomas D. Outcome after one previous caesarean section. J Obst Gynaecol 1994; 14:415-9

8. Anjoo Agarwal, Poonam Chowdhary,Vinita Das. Evaluation of pregnant women with scarred uterus in a low resource settingsep. 2007;3:651-54

9. McMohan MJ, Luther ER, Bowes WA, Olshan AF, Comparison of a trial of labour with an elective second caesarean section. N Engl J Med 1996;335:689-95

10. Khan KS, Rizvi A. The partograph in the management of labour following caesarean section. Int J Gynaecol Obstet 1995;50:151-7

11. Tariq RA. Vaginal delivery after previous caesarean section. J CPSP 1995;5:174-6

12. Najmi R S, Factor Determining Route of Delivery Following One Caesarean Section, JCPSP 9;(1) 20-23

13. A Cahill, D Stamilio, A Odibo. Is vaginal birth after cesarean (VBAC) or elective repeat cesarean safer in women with a prior vaginal delivery / American Journal of Obstetrics andGynaecology,2006;195:1143-47

14. Hibbard JU, Gilbert S, Landon MB, Hauth JC, Leveno KJ, Spong CY, et al. Trial of labor or repeat cesarean delivery in women with morbid obesity and previous cesarean delivery. Obstet Gynecol 2006;108:125-33.

15. Goodall PT, Ahn JT, Chapa JB, Hibbard JU. Obesity as a risk factor for failed trial of labor in patients with previous cesarean delivery. Am J Obstet Gynecol 2005;192:1423-6.

16. Juhasz G, Gyamfi C, Gyamfi P, Tocce K, Stone JL. Effect of body mass index and excessive weight gain on success of vaginal birth after cesarean delivery. Obstet Gynecol 2005;106:741-6.

17. HSS. Report on confidential enquiries into maternal death in England and Vales 1982-1984. London: HMSO 1989;34:87-95

18. Dutta DC. Pregnancy with history of previous cesarean section. Textbook of obstetrics including perinatology and contraception. 7th edition, 2011:327-31.

19. Chowdhury SB, Newaz R, Begum A, Dewan F. Indications and complications of cesarean section-A study of 1083 cases, Bangladesh J Obstet Gynecol 1994;9:1-7.

20. Roberts LJ, Beardsworth SA, Trew G. Labour following caesarean section: current practice in UK. Br J Obst Gynaecol 1994;101:153-55

21. Onankpa B, Ekele B. Fetal outcome following cesarean section in a university teaching hospital. J Natl Med Assoc. 2009;101:578-81. 